\title{
More Than Just a Case of Polymyalgia Rheumatica
}

\author{
João Pereira ${ }^{1}$, Gisela Eugénio ${ }^{2}$, Suzana Calretas ${ }^{1}$, Rui Santos ${ }^{1}$, Armando Carvalho ${ }^{1}$ \\ ${ }^{1}$ Department A of Internal Medicine, Centro Hospitalar e Universitário de Coimbra, Coimbra, Portugal \\ ${ }^{2}$ Department of Rheumatology, Centro Hospitalar e Universitário de Coimbra, Coimbra, Portugal
}

How to cite this article: Pereira J, Eugénio G, Calteras S, Santos R, Carvalho A. More than just a case of polymyalgia rheumatica. EJCRIM 2016;3:doi:10.12890/2016_000374

Conflicts of Interests: The authors declare that there are no competing interests.

This article is licensed under a Commons Attribution Non-Commercial 4.0 License

\section{ABSTRACT}

Malignant neoplasms are associated with a wide range of paraneoplastic rheumatological syndromes. These can be defined as remote effects of cancer, which are not caused by the tumor and its metastasis.

The authors describe the case of an 82-year-old man, who presented with a one-month history of pain, stiffness, and functional limitation of the scapular and pelvic girdles. Blood tests showed raised levels of inflammatory markers.

He was diagnosed with Polymyalgia Rheumatica, but the lack of response to corticosteroids led to the suspicion of an alternative diagnosis, like, for example, an occult neoplasm. Although patient evaluation was initially normal, five months later he developed macroscopic haematuria and was diagnosed with bladder and prostate carcinomas. After surgical treatment, the patient fully recovered from his rheumatological syndrome.

\section{LEARNING POINTS}

- In cases when polymyalgia rheumatica exhibits atypical clinical features and/or therapeutic resistance, additional investigation is recommended.

- Paraneoplastic syndromes can lead to the diagnosis of an underlying neoplasm.

\section{KEYWORDS}

Polymyalgia rheumatica, paraneoplastic syndromes, bladder neoplasm.

\section{INTRODUCTION}

Paraneoplastic syndromes are associated with a wide range of diseases and/or symptoms that are not caused directly by the tumour or its metastases. They can result from the action of hormones, cytokines, and other substances produced by neoplastic cells, or are the consequence of the host's mechanisms directed against these cells. These manifestations tend to occur at sites that are distant from the tumour ${ }^{[1]}$. Some may consist of a variety of musculoskeletal pathologies, and are, therefore, defined as paraneoplastic rheumatologic syndromes.

Polymyalgia rheumatica (PMR), a relatively common disease in the elderly, is characterized by stiffness and pain in the shoulders, neck, and hips.

The association between PMR and cancer is controversial, and it is based on temporal concurrence and corresponding clinical course between the two pathologies. Associations between PMR and haematological and solid malignant tumours have been described ${ }^{[2]}$. Paraneoplastic syndromes are important as they can represent the first presentation of an associated,and often occult, neoplasm ${ }^{[3]}$. 


\section{CASE REPORT}

A 82-year-old man was admitted to the Emergency Department with a one-month history of pain, stiffness, and decreased range of motion affecting both shoulders and hips, which greatly limited daily activities. The patient had a past medical history of type 2 diabetes mellitus and essential hypertension, and was under medication with metformin $1000 \mathrm{mg}$ twice daily, gliclazide $60 \mathrm{mg} / \mathrm{day}$, and lisinopril $20 \mathrm{mg} / \mathrm{day}$. Physical examination was remarkable for pain with movement and a markedly decreased active range of motion of the shoulder griddle. Laboratory tests (Table 1) revealed a normochromic, normocytic anaemia, an erythrocyte sedimentation rate (ESR) of $76 \mathrm{~mm} / \mathrm{h}$, and a C-reactive protein (CRP) 17.9x the upper limit of normal (ULN). The remaining laboratory tests, including serum protein electrophoresis, antinuclear antibodies, $\mathrm{c}$ and $\mathrm{p}$-ANCAs, complement fractions, rheumatoid factor, and anti-CCP antibody, were unremarkable. Diagnosis of PMR was considered and deflazacort $12 \mathrm{mg}$ /day was started.

\begin{tabular}{|c|c|c|c|c|c|c|}
\hline \multirow{4}{*}{$\begin{array}{l}\text { 들 } \\
8 \\
\text { ㅁ } \\
\text { 음 } \\
\overline{\overline{3}} \\
\end{array}$} & Haemoglobin $(13-17 \mathrm{~g} / \mathrm{dl})$ & 11.3 & \multirow{10}{*}{ 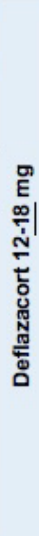 } & 12.6 & \multirow{10}{*}{ 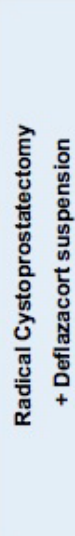 } & 12.8 \\
\hline & MCV (83-101 fL) & 94.9 & & 92.6 & & 95.3 \\
\hline & Leukocytes $\left(4-10 \times 10^{\wedge} 9 / L\right)$ & 9.9 & & 10.5 & & 7.5 \\
\hline & $\operatorname{ESR}(1-20 \mathrm{~mm} / \mathrm{h})$ & 76 & & 53 & & 38 \\
\hline \multirow{8}{*}{ 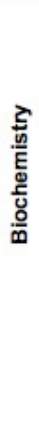 } & CRP $(0-0.5 \mathrm{mg} / \mathrm{dl})$ & 8.95 & & 8.93 & & 0.28 \\
\hline & LDH (125-220 U/L) & 158 & & 171 & & 158 \\
\hline & CPK (<171 U/L) & 38 & & 66 & & 69 \\
\hline & ALP (40-150 U/L) & 106 & & 84 & & 112 \\
\hline & $\begin{array}{l}\text { Creatinine }(0.72-1.18 \\
\mathrm{mg} / \mathrm{dl})\end{array}$ & 0.84 & & 1.11 & & 1.01 \\
\hline & Ferritin $(20-250 \mathrm{ng} / \mathrm{ml})$ & 255 & & - & & 50 \\
\hline & $\mathrm{HbA} 1 \mathrm{c}(\%)$ & 7.7 & & 8.0 & & 7.8 \\
\hline & $\mathrm{PSA}(<4 \mathrm{ng} / \mathrm{ml})$ & 1 & & 1.1 & & $<0.1$ \\
\hline
\end{tabular}

Table 1. Laboratory test results. Deflazacorte dosage is underlined.

Treatment improved some of the patients' complaints but failed to achieve complete symptom relief. Laboratory test results showed a mild decrease on ESR, with values between $53-59 \mathrm{~mm} / \mathrm{h}$, while CRP values remained unchanged (Table 1). Deflazacort was then increased to $18 \mathrm{mg} /$ day (with a "tighter" surveillance of glycaemic control) without further improvement.

Prompt investigation was carried out for an alternative diagnosis, and included Prostatic Specific Antigen (PSA), gastrointestinal endoscopy, chest $x$-ray, and abdominal ultrasound, all of which were unremarkable.

Five months later, the patient sought medical care for an acute episode of macroscopic haematuria. Further study with abdominal ultrasound (Fig. 1) showed a bladder mass (previously absent) that was confirmed by computed tomography scan to be suggestive of a bladder carcinoma extending to the surrounding fatty tissue layer (Fig. 2).

Radical cystectomy and prostatectomy were carried out and histology confirmed an infiltrative bladder carcinoma - T3bN1M0 - and a previously unknown prostate adenocarcinoma - pT2aNOMO, Gleason 6.

A few weeks after surgery, deflazacort was suspended, and one month after discharge, the patient was asymptomatic and his inflammatory markers had improved: ESR of $38 \mathrm{~mm} / \mathrm{h}$ and CRP were negative.

\section{DISCUSSION}

Paraneoplastic syndromes affect up to $8 \%$ of patients with an active cancer, most of the times preceding its diagnosis ${ }^{[1,2]}$. Its pathophysiology is not fully understood, but in the last decades, some mechanisms linking cancer to these syndromes have become clearer. It is accepted that soluble factors produced by the tumour and/or an immune/host reaction against tumour cells are involved ${ }^{[1,4]}$.

These soluble factors can be peptides or hormones, the latter being the most important mechanism in endocrine paraneoplastic syndromes, such as Cushing syndrome. Immune-mediated paraneoplastic syndromes (e.g. rheumatologic paraneoplastic syndromes) are believed to be the result of a host's immunologic response against an underlying neoplasia. It has become clearer that tumour cells can adapt themselves in order to evade immunologic-driven destruction, in a process that was named "immunoediting" by Dunn and colleagues ${ }^{[5]}$. This process has three stages: elimination, equilibrium, and escape. In the first stage, the immune response succeeds in eliminating the neoplasm; in the second stage, equilibrium between immune destruction and tumour growth is reached, preventing tumour development without eliminating 

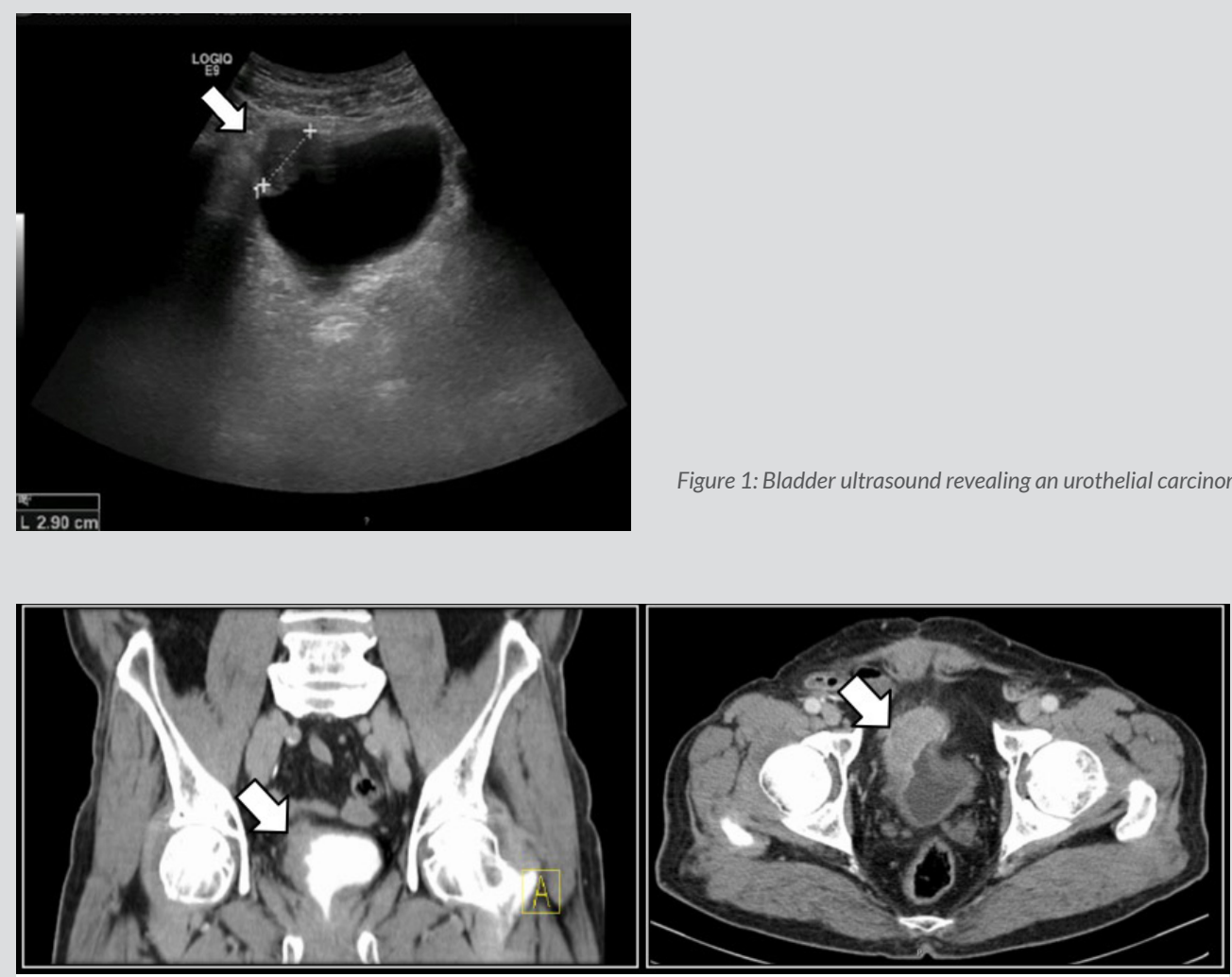

Figure 2: Abdominal computed tomographyscan showing an invasive urothelial carcinoma of the bladder (white arrows).

it; and in the last stage, tumour cells manage to evade the immune system control and the tumour grows unrestrained. In the first two stages, the likely scenario is of an occult neoplasia and, therefore, patients are often diagnosed with clinical syndromes resulting from the distal manifestations of the underlying tumour, such as the case of paraneoplastic PMR.

Diagnosis of paraneoplastic rheumatic syndromes is therefore challenging, and is based on a time-relation scenario and some unusual manifestations of the presenting inflammatory musculoskeletal disease, such as rapid/agressive-onset of symptoms, atypical age group, poor response to corticosteroids or immunosuppressive therapy, atypical distribution of involved joints, and abnormal laboratory tests. Commonly associated neoplasms are haematolymphatic malignancies (1/3 of patients), followed by adenocarcinoma of the lung and breast (among others) ${ }^{[1,3]}$. A group of reported cases in the literature linking PMR to malignant neoplasms is summarized in Table 2 - Appendix.

In the present case, the lack of response to treatment and the improvement/resolution of the patient's complaints after surgery established the relationship between PMR and the underlying urothelial cancer/prostate adenocarcinoma, thus leading to the diagnosis of a paraneoplastic polymyalgia rheumatica.

Atypical PMR and, especially the lack of a dramatic treatment response, should prompt additional investigation for alternative diagnosis. Recognition of paraneoplastic rheumatic diseases may permit early diagnosis and treatment of the underlying cancer, as these syndromes, although rare, can be the first sign of an occult malignancy or its recurrence ${ }^{[3]}$.

\section{REFERENCES}

1. Manger B, Schett G. Paraneoplastic syndromes in rheumatology. Nat Rev Rheumatol 2014;10:662-70.

2. Pelosof L, and Gerber D. Paraneoplastic Syndromes: An Approach to Diagnosis and Treatment. Mayo Clin Proc 2010;85:838-854.

3. Azar L, Khasnis A. Paraneoplastic rheumatologic syndromes. Curr Opin Rheumatol 2013;25:44-9.

4. Shah AA, Casciola-Rosen L, Rosen A. Review: cancer-induced autoimmunity in the rheumatic diseases. Arthritis Rheumatol 2015;67:317-26.

5. Dunn GP, Bruce AT, Ikeda H, Old LJ, Schreiber RD. Cancer immunoediting: from immunosurveillance to tumor escape. Nat Immunol 2002;3:991-8. 


\section{APPENDIX}

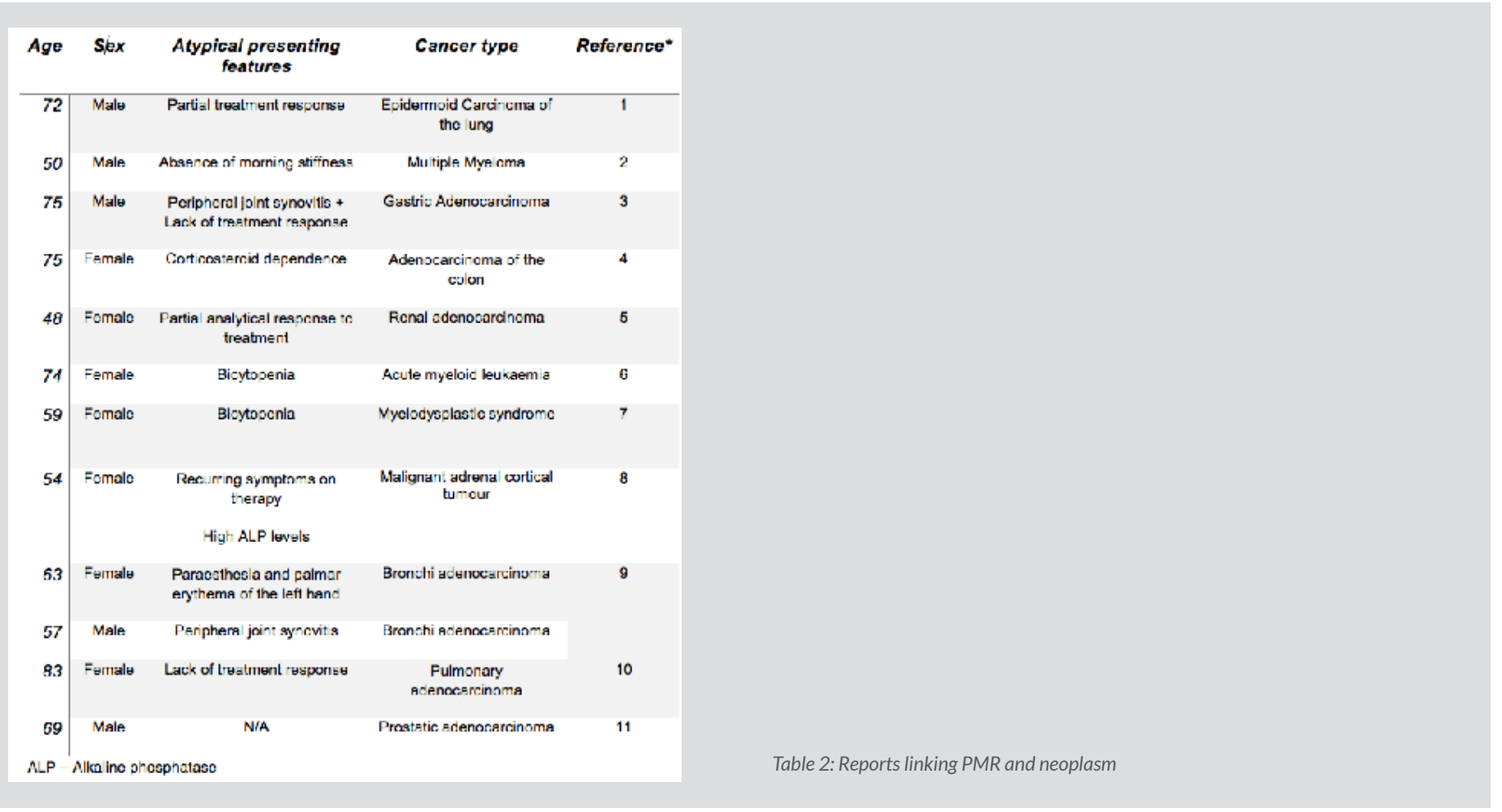

\section{APPENDIX REFERENCES}

1. Fernández Guerra J, Barrot Cortés E, Soto Campos J.G. Polimialgia reumática como forma de presentación de un carcinoma epidermoide pulmonar. Arch Bronconeumol 1996;32:155.

2. Suzuki S, Ikusaka M, Miyahara M, Shikino K. Positron emission tomography findings in a patient with multiple myeloma of polymyalgia rheumatica-like symptoms caused by paraneoplastic syndrome. BMJ Case Rep 2014. pii: bcr2013203326.

3. Yasunaga Y, Miyashita T, Makiyama J, Koga T, Izumi Y, Kitazato A, et al. Clin Exp Rheumatol 2010;28:111-2.

4. Kehler T, Curković B. Polymyalgia rheumatica and colon malignacy: case report. Clin Rheumatol 2006;25:764-5.

5. Härkönen M. Polymyalgia rheumatica ja munuaiskarsinooma. Duodecim 1998;114:1729.

6. Anton E. More on Polymyalgia Rheumatica (PMR) as a Paraneoplastic Rheumatic Syndrome in the Elderly (Bicytopenia and PMR Preceding Acute Myeloid Leukemia). J Clin Rheumatol 2007;13:114.

7. Mok, C, Lau S, Kuman C. Polymyalgia Rheumatica as the Rheumatological Manifestation of Myelodysplastic Syndrome in a Chinese Patient. Br J Rheumatol 1995;35:496-497.

8. Siebert S, Lawson TM, Wheeler MH, Martin JC, Williams BD. Polymyalgia rheumatica: pitfalls in diagnosis. J R Soc Med 2001;94:242-244.

9. Cocquempot K, Defuentes G, Duron-Martineau S, Berets O, Vaylet F, Margery J. Polymyalgia rheumatica revealing a lung cancer. Rev Mal Respir 2013;30:67-70.

10. Masin N, Buchard PA, Gerster JC. Polymyalgia rheumatica and pulmonary cancer: paraneoplastic syndrome. Rev Rhum Mal Osteoartic 1992;59:153-4.

11. Hakkou J, Rostom S, Bahiri R, Hajjaj-Hassouni N. Paraneoplastic rheumatic syndromes: report of eight cases and review of literature. Rheumatol Int 2012;32:1485-9. 